\title{
International Conference on
}

\section{Scholarly Information Network}

\author{
By Sachié Noguchi \\ Assistant Japanese Librarian \\ University of Illinois at Urbana-Champaign
}

\section{East Asian applications and international cooperation,} Tokyo, December 8-11, 1987.

$I_{1}$ tional and universty nagressed, and the number of machine-readable bibliographic records has grown rapidly. For instance, in Japan, in addition to JAPAN MARC distributed by the National Diet Library, bibliographic information on academic and research materials is created and distributed by the National Center for Science Information System (NACSIS) under the banner of the Scholarly Information System.

Chinese characters are used in Chinese, Japanese, and Korean languages; however, they are read differently and have developed variant forms within each language community. In addition to the adopted Chinese system of writing, the Japanese use a syllabic script called kana and the Koreans employ hangul. Each language community developed each two-byte (except CCCII in Taiwan) character set code independently and there has been little discussion concerning exchange of information about the Chinese character set code or about bibliographic data among East Asian countries.

On the other hand, in North America, the Research Library Group (RLG) developed and inaugurated the bibliographic network system which is capable of processing Chinese, Japanese, and Ko- rean (CJK) scripts as an RLIN subsystem. This was done in cooperation with the Library of Congress in 1983. More than 300,000 bibliographic records have already been accumulated. The Online Computer Library Center (OCLC) launched its CJK subsystem in May 1986. These two CJK systems are used by thirty-four libraries in North America and by the British Library. Both RLIN and OCLC CJK subsystem use a three-byte character code, the RLIN East Asian Character Code (REACC), and it is expected that the REACC will be established as the "American National Standard, East Asian Character Code set for Bibliographic Use." Its thesaurus is under the administration of the Library of Congress.

Utlas International Canada introduced the system into Japan in 1985 and it is used mainly among private university libraries. In 1987, Utlas developed Japan CATSS as a bibliographic utility specifically for Japanese language materials. It uses modified JAPAN MARC format and the same character set as the National Diet Library of Japan (Japan Industrial Standard C6226 1978, two-byte).

It was obviously time to coordinate the standardization and stabilization of character set and bibliographic data among East Asian countries to facilitate the future exchange of data among themselves and across the Pacific. NACSIS of Japan took 
the initiative to organize the first International Conference on Scholarly Information NetworkEast Asian Applications \& International Cooperation-on December 8-11, 1987, by inviting interested parties to Tokyo to discuss the problems involved and attempt to reach a consensus on these issues.

The conference took place at NACSIS and at the National Diet Library. Seventeen invited panelists attended from Japan, and sixteen from Hong Kong, Korea, the People's Republic of China, Taiwan, the Federal Republic of Germany, the United Kingdom, the United States, and Canada. There were also fifteen observers from Japan and the United States. Among the North American members of the panel were C. James Schmidt (RLIN), Rowland C.W. Brown and Andrew H. Wang (OCLC), Robert F. Asleson and N. Furuya (Utlas International Canada), Beacher Wiggins (Library of Congress), and C.J. Durance (National Library of Canada).

The discussion at the conference was based on the six position papers and the eighteen that commented on them. These were distributed to the participants before the conference. Round Table 1 was entitled "Improvement of International Exchange of Scholarly Information." Round Table 2 dealt with the technical issues of East Asian character set codes. An open forum for the public catered for the growing interests in bibliographic utilities among the Japanese library community. Utlas and OCLC have made inroads into the Japanese mar- ket, and they and the British Library, RLIN, and NACSIS made introductory presentations to mainly Japanese audiences.

There are two technical committees (TC 97 and TC 46) working on character sets within International Standardization Organization (ISO), and it was felt that they should either be amalgamated or responsibility be given only to one. The International Organizing Committee agreed to submit a "review paper" to ISO on this matter. The necessity for a coordinating body of national standards of character set was expressed by a quite few members represented by the proposals from LC, International Committee on Character Bet Coordination, and NACSIS, Clearing Center for Chinese Character Users in East Asian environment. The Committee unanimously agreed to continue the dialogue and cooperative efforts for the international exchange of scholarly information in the future.

Today, technology has blurred national boundaries, and cultural and language demarcation are no longer quite so clearly defined. By bringing together the major bibliographic utilities and other bodies involved in the area, this conference offered a precious opportunity for promoting mutual understanding and sharing the common issues. It was a crucial, constructive step towards coordinating the basis for bibliographic data communication containing East Asian scripts, and for international scholarly information exchange of such data between East Asia, North America, and Europe.

\title{
RESEARCH PUBLICATIONS
}

\section{Guaranteed availability, when you want them.}

\author{
Journals of Science, Technology, \\ and Medicine in microform.
}

Every title filmed and delivered - from the first issue forward. Current subscriptions are delivered within three months of the end of the volume year, and availability of all backfiles is guaranteed. For complete title listings and prices, call 1-800-REACH-RP (1-800-732-2477) now. From Connecticut, Alaska and Canada, call collect (203) 397-2600.

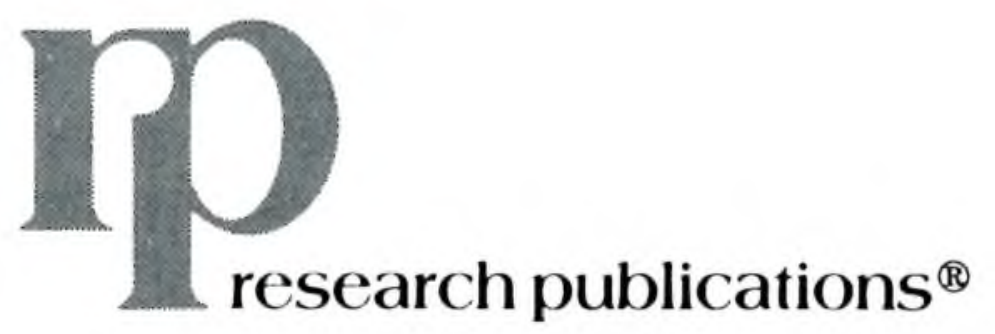

Research Publications, Inc. 